\title{
The network of invasive cardiology facilities in Poland in 2016 (data from the ORPKI Polish National Registry)
}

\author{
Paweł Kleczyński ${ }^{1}$, Zbigniew Siudak ${ }^{2}$, Artur Dziewierz ${ }^{1}$, Tomasz Tokarek ${ }^{2}$, Tomasz Rakowski ${ }^{1}$, \\ Jacek Legutko ${ }^{1}$, Stanisław Bartuś ${ }^{1}$, Dariusz Dudek ${ }^{1,2}$ \\ $2^{1}{ }^{\text {nd }}$ Department of Cardiology, Jagiellonian University Medical College, Krakow, Poland \\ ${ }^{2}$ Department of Interventional Cardiology, Jagiellonian University Medical College, Krakow, Poland
}

\section{INTRODUCTION}

Despite significant advancements in cardiac care, cardiovascular diseases (CVDs) are the main cause of mortality in Poland. Thus, they should be a priority in the national health policy. In addition, further optimisation of medical care requires maintenance of an effective, integrated, and networked structure of the treatment of CVDs. In Poland, treatment of coronary artery disease, including acute coronary syndrome (ACS), is currently provided complimentarily by a network of high- and low-volume percutaneous coronary intervention (PCl) centres. Importantly, the network has been organised and developed by Polish cardiologists for almost 20 years. During that period, multiple strategies have been introduced to improve the safety and efficacy of national care for patients with ACS. These have included a reduction of the time from first medical contact to reperfusion through an increase in the availability of primary- $\mathrm{PCl}$ centres, direct transfer, bypassing non-PCl-capable hospitals or emergency departments, and early cath lab activation after electrocardiogram teletransmission from the field [1-5]. Despite this, approximately 50\% of patients with ST-segment elevation myocardial infarction (STEMI) are still not transferred directly to the appropriate facility and may experience an unnecessary delay to reperfusion $[3,4]$. Thus, regional and countrywide systems of care face an ongoing challenge of determining the best policies for geographical distribution of cath labs and time frames of transferring the patients from referring centres to primary-PCI hospitals. Data on the current activity and geographical distribution of cath labs may be helpful to refine the network. Thus, we sought to evaluate the current number, performance, and localisation of $\mathrm{PCI}$ facilities in Poland, based on data from the Polish National PCI Registry (ORPKI).

\section{METHODS}

The ORPKI Registry is operated by the Jagiellonian University Medical College in Krakow, Poland (https://www.orpki.cm-uj. krakow.pl/) and is endorsed by the Polish Association of Cardiovascular Interventions of the Polish Cardiac Society (AISN PTK) [6]. The registration in the ORPKI database is voluntary; however, as much as $98 \%$ of all catheterisation laboratories in Poland have joined the registry. For this study, complete data for 2016 collected from 157 cath labs were extracted. The centres were divided into high-volume $(\geq 400 \mathrm{PCls} /$ year) and low-volume ( $<400 \mathrm{PCls} /$ year), depending on the total number of all PCls performed in a particular cath lab in 2016. A cut-off value of $400 \mathrm{PCls} /$ year was selected, as recommended by the European Society of Cardiology (ESC) guidelines on myocardial revascularisation [6]. In addition, data from the highest-volume centres, according to a cut-off value of $1000 \mathrm{PCls} / y e a r$, were assessed. Subsequently, data concerning numbers of $\mathrm{PCl}$ were stratified by the initial diagnosis.

\section{RESULTS AND DISCUSSION}

In 2016, 115,790 PCls were performed in 157 cath labs in Poland. On average, each invasive cardiology facility provided care for a mean of 239,000 inhabitants. A total of 26 centres performed < $400 \mathrm{PCls} /$ year $(5604 \mathrm{PCls}, 22 \%$ STEMI, 22\% non-STEMI [NSTEMI], 27\% unstable angina, 27\% stable angina), and 131 centres performed $\geq 400 \mathrm{PCls} /$ year (110,186 PCls, 19\% STEMI, 17\% NSTEMI, 31\% unstable angina, $32 \%$ stable angina). $4.8 \%$ of all $\mathrm{PCl}$ procedures were performed in low-volume centres, which comprised $17 \%$ of all $\mathrm{PCl}$ centres. Notably, $72.5 \%$ of $\mathrm{PCl}$ in low-volume centres were performed in patients with ACS. The distribution of cath labs depending on the number of $\mathrm{PCls} /$ year

\section{Address for correspondence:}

Paweł Kleczyński, MD, PhD, Institute of Cardiology, University Hospital, ul. Kopernika 17, 31-501 Kraków, Poland, tel: +48 124247181 , fax: +48 124247184 e-mail: kleczu@interia.pl

Received: 27.09.2017 Accepted: 19.01.2018

Kardiologia Polska Copyright (c) Polish Cardiac Society 2018 


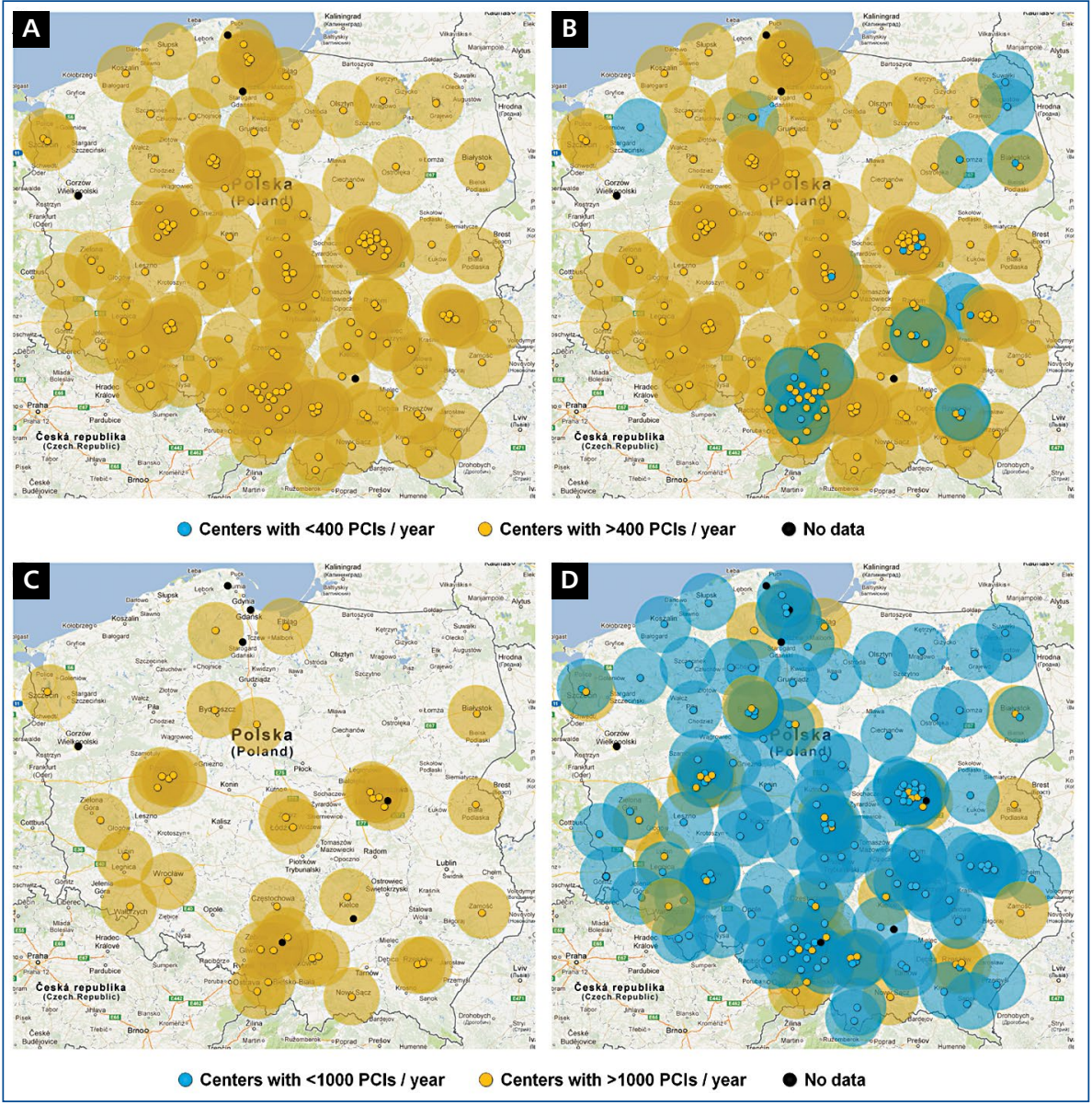

Figure 1. Map of Poland with the geographical distribution of cath labs depending on the number of percutaneous coronary interventions (PCls) performed in 2016; A. Centres with $\geq 400 \mathrm{PCls} / \mathrm{year}$; B. Additionally added centres with $<400 \mathrm{PCls} / \mathrm{year}$; C. Centres with $\geq 1000 \mathrm{PCls} /$ year; D. Additionally added centres with $<1000 \mathrm{PCls} /$ year. Marked hypothetical areas providing possible transfer and $\mathrm{PCI}$ for patients with acute myocardial infarction within 90 min from the first medical contact

is presented in Figure $1 \mathrm{~A}, \mathrm{~B}$. A total of 32 centres performed > 1000 PCls/year (42,533 PCls, 15\% STEMI, 14\% NSTEMI, 34\% unstable angina, 36\% stable angina) and 125 centres performed $<1000$ PCIs/year $(73,257$ PCls, $22 \%$ STEMI, 19\% NSTEMI, 30\% unstable angina, 29\% stable angina; Fig. 1C, D).

The current report underlines the importance of low-volume $\mathrm{PCl}$ centres operating on a $24 / 7$ basis in providing cardiovascular care for patients in Poland. Despite the fact that only $4.8 \%$ of all PCls were performed in low-volume PCl centres, these centres seem to be crucial in providing care to patients presenting with ACS. The distribution of complementary highand low-volume centres corresponding to population density seems to be optimal for the covered regions. In 2016, those 160 (157 reporting centres) cath labs operating 24/7 provided cardiac care for an average of 239,000 inhabitants. These numbers are consistent with the requirements of AISN PTK and ESC guidelines [7-9]. To build an effective system of STEMI care, partnerships between STEMI-referral hospitals, primary-PCI hospitals, and emergency system teams are critical (a so-called "hub-and-spoke" system) [10]. Networks for STEMI and ACS treatment allow a reduction of the time from the onset of symptoms to reperfusion [5]. Importantly, further reduction of delay to reperfusion is crucial because the prolongation of time to reperfusion may adversely affect outcomes [5]. Thus, the main rationale for the support of low-volume $\mathrm{PCl}$ centres is their geographical availability. The reduction in time from the first medical contact to balloon inflation depends on the pattern in which the patient is referred to the cath lab [5]. In addition, close cooperation between primary-PCl facilities, non-PCl-capable hospitals, and emergency medical services may allow optimisation of pre-hospital treatment of ACS patients [11]. The total number of $\mathrm{PCl}$ procedures in each centre is also dependent on the type of the contract with the National Health Service. Low-volume centres have a limited financial contract for elective procedures and have been able so far to perform urgent PCls without limits. 
Despite differences in the number of procedures performed in $\mathrm{PCl}$ centres, from the geographical perspective, low-volume facilities are equally as important as the high-volume ones because they especially serve patients presenting with ACS. Distribution of high- and low-volume centres seems optimal. However, in the perspective of an ageing population, further efforts are needed to enhance cardiovascular care networks.

\section{Conflict of interest: none declared}

\section{References}

1. Bagai A, Al-Khalidi HR, Muñoz D, et al. Bypassing the emergency department and time to reperfusion in patients with prehospital ST-segment-elevation: findings from the reperfusion in acute myocardial infarction in Carolina Emergency Departments project. Circ Cardiovasc Interv. 2013; 6(4): 399-406, doi: 10.1161/CIRCINTERVENTIONS.112.000136, indexed in Pubmed: 23861465.

2. Kawecki D, Gierlotka M, Morawiec B, et al. Direct Admission Versus Interhospital Transfer for Primary Percutaneous Coronary Intervention in ST-Segment Elevation Myocardial Infarction. JACC: Cardiovascular Interventions. 2017; 10(5): 438-447, doi: 10.1016/j.jcin.2016.11.028.

3. Fosbol EL, Granger CB, Jollis JG, et al. The impact of a statewide pre-hospital STEMI strategy to bypass hospitals without percutaneous coronary intervention capability on treatment times. Circulation. 2013; 127(5): 604-612, doi: 10.1161/CIRCULATIONAHA.112.118463, indexed in Pubmed: 23275382.

4. Boothroyd LJ, Lambert LJ, Segal E, et al. Comparison of outcomes of ambulance users and nonusers in ST elevation myocardial infarction. Am J Cardiol. 2014; 114(9): 1289-1294, doi: 10.1016/j. amjcard.2014.07.060, indexed in Pubmed: 25201215.

5. Dudek D, Legutko J, Siudak Z, et al. [Invasive treatment strategies in patients with myocardial infarction in Poland].
Kardiol Pol. 2010; 68(5): 618-624; discussion 625, indexed in Pubmed: 20491040.

6. Legutko J, Siudak Z, Parma R, et al. Poland: coronary and structural heart interventions from 2010 to 2015. EuroIntervention. 2017; 13(Z): Z51-Z54, doi: 10.4244/EIJ-D-16-00836, indexed in Pubmed: 28504231.

7. Windecker S, Kolh P, Alfonso F, et al. Authors/Task Force members. 2014 ESC/EACTS Guidelines on myocardial revascularization: The Task Force on Myocardial Revascularization of the European Society of Cardiology (ESC) and the European Association for Cardio-Thoracic Surgery (EACTS)Developed with the special contribution of the European Association of Percutaneous Cardiovascular Interventions (EAPCI). Eur Heart J. 2014; 35(37): 2541-2619, doi: 10.1093/eurheartj/ehu278, indexed in Pubmed: 25173339.

8. Dudek D, Legutko J, Ochała A, et al. [Guidelines of the Association of Cardiovascular Interventions of the Polish Cardiac Society for certification of coronary diagnosts and percutaneous coronary intervention operators and invasive cardiology centers in Poland]. Kardiol Pol. 2013; 71(12): 1332-1336, doi: 10.5603/KP.2013.0344, indexed in Pubmed: 24399604.

9. Ochała A, Siudak Z, Legutko J, et al. Percutaneous interventions in cardiology in Poland in the year 2014. Summary report of the Association of Cardiovascular Interventions of the Polish Cardiac Society AISN PTK. Post Kardiol Interw. 2015; 11(3): 177-181, doi: 10.5114/pwki.2015.54009, indexed in Pubmed: 26677356.

10. Steg PhG, James SK, Atar D, et al. ESC Guidelines for the management of acute myocardial infarction in patients presenting with ST-segment elevation. Eur Heart J. 2012; 33(20): 2569-2619, doi: 10.1093/eurheartj/ehs215, indexed in Pubmed: 22922416.

11. Kubica J, Adamski P, Paciorek P, et al. Anti-aggregation therapy in patients with acute coronary syndrome - recommendations for medical emergency teams. Experts' standpoint. Kardiol Pol. 2017; 75(4): 399-408, doi: 10.5603/KP.a2017.0057, indexed in Pubmed: 28421594

Cite this article as: Kleczyński P, Siudak Z, Dziewierz A, et al. The network of invasive cardiology facilities in Poland in 2016 (data from the ORPKI Polish National Registry). Kardiol Pol. 2018; 77(4): 805-807, doi: 10.5603/KP.2018.0081. 